\title{
Characteristics of falls in mild and moderate Alzheimer's disease
}

\author{
Eliane Mayumi Kato-Narita1, Marcia Radanovic ${ }^{2}$
}

\begin{abstract}
The occurrence of falls in AD patients is frequent, and their consequences are cognitive decline, fractures and loss of independence. Many studies have addressed fall risk factors in order to establish effective prevention strategies. Objectives: We describe the frequency and characteristics of falls in a sample of AD patients and their main risk factors. Methods: We evaluated 40 subjects without cognitive impairment, and $45 \mathrm{AD}$ patients, graded as CDR 1 and CDR 2. Results: Environmental hazard risks were the most frequent cause associated with falls in CDR $1(41.4 \%)$ and CDR 2 (46.7\%). Instability (31\%) and dizziness (17.2\%) were frequent causes of falls in the CDR 1 group, and this group showed the highest rate of recurrence (28\%). In both groups of AD patients, indoors falls predominated (70.3 and 80\% respectively for CDR 1 and 2). In our sample, the remaining factors studied were not associated with increasing risk for falls. Conclusions: These results reinforce the hypothesis that falls in $\mathrm{AD}$ are mutifactorial and that their risk factors are highly interconnected. Preventative strategies considering all aspects should be implemented most crucially eliminating environmental risks, maintaining constant presence of caregivers, and providing physical and functional stimulation, both in mild and moderate AD. Key words: falls, elderly, Alzheimer's disease.
\end{abstract}

\begin{abstract}
Características das quedas na doença de Alzheimer leve e moderada
Resumo - Fundamentos: A ocorrência de quedas entre idosos com a doença de Alzheimer (DA) é muito frequente, e traz consequências graves como a piora cognitiva, fraturas e perda da independência. Muitos estudos foram realizados com o objetivo de identificar os fatores de risco associados às quedas, com o fim de propor estratégias de prevenção. Objetivos: O presente estudo buscou descrever a frequência e características das quedas em uma amostra de pacientes com DA, e seus principais fatores de risco. Métodos:Foram analisados 40 idosos sem alterações cognitivas e 45 com DA, classificados em CDR 1 e CDR 2. Resultados: Riscos ambientais foram associados às quedas tanto no grupo CDR 1 (41.4\%) como CDR 2 (46.7\%). Instabilidade (31\%) e tontura $(17.2 \%)$ foram frequentes no grupo CDR 1 , sendo este o grupo que apresentou o maior índice de recorrência (28\%). Em ambos os grupos com DA, as quedas ocorreram mais frequentemente dentro de casa (70,30 e $80 \%$ respectivamente para os grupos CDR 1 e 2). Conclusões: Estes resultados reforçam a hipótese de que as quedas em pacientes com DA são multifatoriais e seus fatores de risco altamente interconectados. Medidas preventivas devem ser realizadas, principalmente quanto a retirada de riscos ambientais, a presença constante de cuidador, e a estimulação física e funcional do paciente, tanto na fase leve como na moderada da DA.
\end{abstract}

Palavras-chave:quedas, idosos, doença de Alzheimer.

\section{Introduction}

Falls in the elderly are one of the most frequent causes of incapacity and death. ${ }^{1}$ Many studies have addressed the causes and risk factors for falls in community-dwelling elderly. One such risk factor is the existence of cognitive impairment. ${ }^{2-5}$

Elderly with dementia have a doubled to threefold risk for the occurrence of falls, ${ }^{6}$ probably due to motor

${ }^{1}$ Physiotherapist, MsC, Behavioral and Cognitive Neurology Unit, Department of Neurology, University of São Paulo School of Medicine, São Paulo SP, Brazil. ${ }^{2}$ Neurologist, MD, PhD, Behavioral and Cognitive Neurology Unit, Department of Neurology, University of São Paulo School of Medicine, São Paulo SP, Brazil.

Eliane Mayumi Kato-Narita - Rua Rondinha 92 / ap 134 - 04140-010 São Paulo SP - Brazil. E-mail: elimkato@yahoo.com.br

Disclosure: The authors report no conflicts of interest.

Received October 03, 2009. Accepted in final form November 13, 2009. 
impairment, ${ }^{7}$ attentional deficits, ${ }^{8}$ use of psychotropic medication and behavioral symptoms. ${ }^{9-11}$ Other risk factors include necessity of a walking-aid, functional impairment, history of recurrent falls, living in long-term residence, and presence of symptomatic orthostatic hypotension. ${ }^{12-14}$

Considering the consequences of falls in dementia (such as functional dependency, progression of the disease and death) and the high social cost and burden of caregivers, many studies have attempted to identify the risk factors for falls and to develop fall prevention strategies. ${ }^{15,16}$ However, studies on risk factors fail to consider the stage of dementia and most have been conducted in dementia care centers or hospitals, and therefore did not address patients who were living in their own homes. These reasons might have led to negative results in prevention strategies.

The objective of this study was to describe the frequency and characteristics of falls and their main risk factors in a sample of Alzheimer's disease (AD) elderly, according to severity of the disease (CDR 1 and CDR 2).

\section{Methods}

Participants

All participants were 60 years and older and of both genders. Forty five $\mathrm{AD}$ patients were recruited from an outpatient service at a university hospital. The diagnosis of AD was based on NINCDS-ADRDA criteria. ${ }^{17}$ The Clinical Dementia Rating (CDR) was used to stage the severity of $\mathrm{AD}$, classifying the disease into mild and moderate $\mathrm{AD}$ (CDR 1 and 2). ${ }^{18}$

The control group included forty elderly without cognitive impairment, recruited from the community and assessed by two neurologists, based on the criteria of the Mayo Older Normative Studies. ${ }^{19}$

For both groups, the exclusion criteria were: presence of vertigo or dizziness, vestibulopathy, episodes of loss of consciousness, other neurological diseases (stroke, Parkinson's disease or parkinsonism, other causes of dementia), untreated depression, uncorrected visual impairment, severe hypoacusia and musculoskeletal alterations with limiting pain.

The study was approved by the local Ethics Committee (CAPPesq 311/04). All participants and/or their legal representatives signed an informed consent term prior to enrollment on the study.

\section{Procedures}

All participants answered a questionnaire containing social-demographic data, and questions concerning the use of medications, walking-aids, as well as history of falls in the last twelve months along with their characteristics. Falls were described to caregivers as any event in which the elderly unintentionally came to rest on the floor or on a lower level to which he or she was standing, regardless of whether or not an injury was sustained. The MMSE was applied to patients and controls as the initial part of the cognitive assessment.

Controls and $\mathrm{AD}$ caregivers answered the functional questionnaire Disability Assessment for Dementia (DAD) $)^{20}$ and the Cornell depression scale ${ }^{21}$ in order to establish the functional status and the presence of depressive symptoms in both groups (patients and controls).

\section{Data analysis}

Descriptive statistical analyses (mean, standard deviation, minimum and maximum values) were performed for demographic data and variables of interest (MMSE, duration of disease, Cornell, DAD and number of falls). Comparison of means among the three groups (controls, CDR 1 and CDR 2) was performed using one-way ANOVA with Tukey's post-test. Student's $t$ test was employed for independent samples to compare continuous variables between two groups (CDR 1 and CDR 2). The distribution of frequencies for categorical variables (marital status, gender, use of medication, occurrence and recurrence of falls) was analyzed through the Chi-square test.

The sample was then subdivided into "fallers" and "non fallers" groups (maintaining the CDR classification within the two groups), and logistic regression analysis was performed in order to identify the risk variables for the occurrence of falls. The level of significance adopted for all analyses was 0.05 .

\section{Results}

\section{Characteristics of the participants}

Table 1 shows the clinical and socio-demographic characteristics of the sample. Differences were observed among the three groups on the MMSE and DAD scores. CDR 2 patients differed from controls on the Cornell scores. There was a higher prevalence of single subjects in the control group. Table 2 shows the use of medications in each group.

\section{Characteristics of falls}

In our study, $45 \%$ of the controls had fallen at least once within the preceding twelve months whilst in the $\mathrm{AD}$ group the frequencies were $56 \%$ and $55 \%$ for $\mathrm{CDR}$ 1 and CDR 2, respectively. Concerning the control group, the number of falls was $0.65 /$ person, and five persons fell more than once. For the CDR 1 group, the number of falls was 1.16/person, and for CDR 2, 0.75; no significant difference between these groups was found. Considering only those who fell ("fallers"), the number of falls was $1.44,2$ 
Table 1. Clinical and socio-demographic characteristics of the control and AD groups.

\begin{tabular}{|c|c|c|c|c|c|}
\hline Variable & Controls $(n=40)$ & CDR $1(n=25)$ & CDR $2(n=20)$ & p (two-tailed) & Multiple comparison \\
\hline Age (years) & $74.5(7.3)$ & $77(7)$ & $77.6(5.5)$ & 0.1810 & - \\
\hline Schooling (years) & $6.6(48)$ & $5.4(4.9)$ & $5.3(4.6)$ & 0.5070 & - \\
\hline \multicolumn{6}{|l|}{ Gender* } \\
\hline M & 18 & 8 & 4 & & \\
\hline $\mathrm{F}$ & 22 & 17 & 16 & 0.1480 & \\
\hline \multicolumn{6}{|l|}{ Marital status ${ }^{*}$} \\
\hline Single & 10 & 0 & 1 & & \\
\hline Married & 13 & 12 & 11 & 0.0060 & \\
\hline Widowed & 12 & 13 & 8 & & \\
\hline Divorced & 5 & 0 & 0 & & \\
\hline Duration of disease $(\mathrm{mo})^{\star \star}$ & NA & $34(25.8)$ & $50.8(30.6)$ & 0.0530 & \\
\hline Primitive reflexes ${ }^{\star}$ & NA & 15 & 12 & 0.0940 & \\
\hline Yes & NA & 10 & 8 & & \\
\hline \multicolumn{6}{|l|}{ No } \\
\hline MMSE & $26.8(3)$ & $18.6(3.9)$ & $13.9(5.3)$ & $<0.0001$ & $\begin{array}{l}\text { All groups differ } \\
\quad(p<0.0001)\end{array}$ \\
\hline Cornell $^{\star *}$ & NA & $2.9(2.7)$ & $3.4(2.3)$ & 0.5670 & - \\
\hline $\mathrm{DAD}$ & $100(0)$ & $80.7(13.6)$ & $67.5(14.9)$ & $<0.0001$ & $\begin{array}{l}\text { All groups differ } \\
\quad(p<0.0001)\end{array}$ \\
\hline
\end{tabular}

One-way ANOVA with Tukey's post-test; ${ }^{\star}$ Chi-square test; ${ }^{*}$ Student's t test; NA, not applicable

Table 2. Number of subjects taking medications in the control and AD groups

\begin{tabular}{lcccc}
\hline Medication & Controls & CDR 1 & CDR 2 & p (two-tailed) \\
\hline Anticholinesterasics & 0 & 24 & 20 & $<0.0001$ \\
Antidepressants & 3 & 9 & 6 & 0.0160 \\
Antipsychotics & 0 & 6 & 6 & 0.0030 \\
Muscular relaxing drugs & 5 & 0 & 0 & 0.0500 \\
Benzodiazepines & 1 & 1 & 0 & 0.6760 \\
Antihypertensives & 19 & 9 & 12 & 0.5710 \\
Antiarritmics & 3 & 0 & 0 & 0.1730 \\
\hline Chi-square test. & & & &
\end{tabular}

and $1.36 /$ person, respectively. Recurrence of falls did not differ between the groups (Table 3 ).

The majority of falls in the CDR 1 group occurred indoors (mostly within the patient's home - 79.3\%), including the yard, and only $20.7 \%$ occurred outdoors (in streets or at unfamiliar places). Similar results were found in the CDR 2 group with frequencies of $80 \%$ and $20 \%$, respectively. The occurrence of indoor falls was statistically more frequent among $\mathrm{AD}$ patients, regardless of disease severity (Table 4).
Environmental hazard risks were the most common cause of falls in our sample, both in CDR 1 and CDR 2 groups, being responsible for $41.4 \%$ and $46.7 \%$ of falls, respectively. Dizziness and instability were more frequently reported as causing falls in the CDR 1 group. For CDR 2 patients, $46.7 \%$ of reported falls had their cause classified as "ignored" or "not remembered". (Table 5)

\section{Risk factors for falls}

In our sample, logistic regression analysis found no as- 
Table 3. Frequency and number of falls occurred in the last twelve months.

\begin{tabular}{lcccc}
\hline Variables & Controls & CDR 1 & CDR 2 & p (two-tailed) \\
\hline Number of falls M (SD) - total group & $0.65(0.9)$ & $1.16(1.5)$ & $0.75(0.8)$ & 0.190 \\
Number of falls M (SD) - “fallers" group & $1.44(0.8)$ & $2(1.5)$ & $1.36(0.6)$ & \\
Occurrence of falls* & & & & 0.622 \\
$\quad$ Yes & $18(45 \%)$ & $14(56 \%)$ & $11(55 \%)$ & \\
$\quad$ No & $22(55 \%)$ & $11(44 \%)$ & $9(45 \%)$ & \\
Recurrence of falls* & & & \\
$\quad$ Yes & $5(12.5 \%)$ & $7(28 \%)$ & $3(15 \%)$ & \\
No & $35(87.5 \%)$ & $18(72 \%)$ & $17(85 \%)$ & \\
\hline
\end{tabular}

Student's t test ${ }^{*}$ Chi-square test.

Table 4. Frequency of falls according to place of the occurrence.

\begin{tabular}{lccc}
\hline Local & Indoors & Outdoors & $\mathbf{p}$ (two-tailed) \\
\hline Controls & $9(50 \%)$ & $9(50 \%)$ & 0.7389 \\
CDR 1 & $23(70.3 \%)$ & $6(30.7 \%)$ & 0.0054 \\
CDR 2 & $12(80 \%)$ & $3(20 \%)$ & 0.0035 \\
\hline
\end{tabular}

Chi-square test

sociation between the variables age, duration of disease, number and type of medications used, presence of primitive reflexes, score on the DAD, score on Cornell or number or frequency of falls (raw data not shown).

\section{Discussion}

Previous studies on falls in the elderly have confirmed the most relevant risk factors as being older age, history of previous falls, necessity of walking aid, presence of visual impairment, high number of drugs (mainly psychotropic drugs), balance disorders and functional impairment. ${ }^{9,14,15,22-26}$

Some of these factors have also been identified in studies with dementia, which have indicated other concurrent risk factors such as high grade periventricular white matter lesions, parkinsonism, peripheral neuropathy, diagnosis of dementia with Lewy body and vascular dementia. ${ }^{7,27-32}$ However, most of these studies did not consider the influence of some variables on the occurrence of falls, such as the etiology of the dementia, study setting (home, hospital or long-term care residences) or the stage of the disease, thus introducing some bias into the results.

This study included only AD patients, a factor that might explain why no powerful single predictor for the occurrence of falls was identified. Studies including various etiologies of dementia may introduce additional variables related to the specificities of each disease, thus making it hard to correctly estimate the impact of a given risk factor on the occurrence of falls.

In Brazil, most elders live in their own residences ${ }^{33,34}$ and not in residential care facilities or long-term care institutions, where many studies on falls have been conducted. It is well known that falls occur more frequently in these places because of lack of supervision, use of more psychotropic drugs to control behavioral disturbances and wandering, besides greater hazard risks ${ }^{35,36}$.

Depending on the severity of the dementia, motor signs are present and can include gait disturbances, extra-pyramidal motor impairment, rigidity and postural instability, all being strongly associated with falls. Moreover, behavioral disturbances such as attentional deficits, wandering and aggressiveness appear in different stages of dementia, contributing to the occurrence of falls. ${ }^{37,38}$ This underscores the importance of analyzing the occurrence of falls and their risk factors according to the stage of dementia.

We found a higher incidence of falls in our non-demented subjects than that described in a previous report in Brazill, ${ }^{4}$ registering approximately $30 \%$. Several factors

Table 5. Causes related to falls in AD patients.

\begin{tabular}{lcccc}
\hline Cause of fall N (\%) & CDR 1 & CDR 2 & total AD group & p \\
\hline Environmental hazard & $12(41.4 \%)$ & $7(46.7 \%)$ & $19(43.1 \%)$ & 0.9157 \\
Dizziness & $5(17.2 \%)$ & $0(0 \%)$ & $5(11.3 \%)$ & 0.4109 \\
Instability & $9(31 \%)$ & $1(6.6 \%)$ & $10(22.6 \%)$ & 0.1464 \\
Ignored & $3(10.4 \%)$ & $7(46.7 \%)$ & $10(22.6 \%)$ & 0.0192 \\
\hline
\end{tabular}

Chi-square test 
reported by our subjects could contribute to this higher incidence of falls, such as the use of public transportation (especially buses), having pets indoors, and climbing chairs to reach objects located in elevated places (such as cabinets).

The frequency of falls in mild and moderate AD (CDR 1 and 2) in our study was similar to that found in other studies, as was the rate of falls per patient. ${ }^{5,6,12-14}$

Eriksson et al. ${ }^{14}$ found that elderly subjects with dementia that use more than four drugs have an increased risk for falls. The number of drugs are reported as a predictor of morbidity and mortality, and probably reflects the poor functional level of the elderly. ${ }^{3}$ Many studies ${ }^{6,10,11,14,30,38,39}$ have described the correlation between use of psychotropic and antidepressants drugs and increased risk of falls, as a result of drowsiness and motor deficits. However, this association was not found in our study.

In our study, almost $80 \%$ of the falls occurred indoors, a result similar to that reported by Soriano et al (77\%). ${ }^{40}$ Mild AD patients remain independent and have less motor impairment, but frequently are not allowed to leave their homes unaccompanied, thus being more exposed to environmental hazard risks during their activities of daily life indoors. Additionally, they may have attentional deficits and poor risk judgment, particularly during gait, as cited by Yamaguchi. ${ }^{41}$

On the other hand, moderate $\mathrm{AD}$ patients have more motor impairments and greater spatial disorientation, demanding the constant presence of a caregiver rendering them even more limited, which might prevent the occurrence of falls outdoors. These patients become more dependent regarding walking and performing functional activities. The fear of falling leads to limitations in mobility in $20 \%$ to $55 \%$ of elderly subjects, and can cause reduction in muscular strength, agility and balance, and loss of independence, ${ }^{40}$ thus further increasing the risk for falls especially if the patient walks unattended.

Loss of functional capacity has been cited as either a cause or a consequence of falls, because of restrictions in mobility and consequent loss of strength and incapacity to perform activities. ${ }^{42,43}$ Although a decline in functional capacity according to DAD scores have been observed in both stages of $\mathrm{AD}$, we found no association between functional disability and the occurrence of falls.

In our study, $43.2 \%$ of falls in the AD group were caused by environmental hazard risks, which caused slips or slides. Analyzing each group, $41.4 \%$ of falls in CDR 1, and $46.7 \%$ in CDR 2 patients were caused by factors such as stairs, wet floor, obstacles and using buses. Soriano et al. ${ }^{40}$ found that almost $30 \%$ of falls were caused by the environment.

The high frequency of this particular risk factor shows that lack of attention might be an important component predisposing individuals to falls, both in mild and moderate $\mathrm{AD}$. These findings show that an important intervention to prevent falls entails keeping the environment safe, in both stages of AD. However, changes in patient's homes should not be so extensive so as to completely modify the characteristics that are familiar to the dweller and which serve as references to the patient, because these can potentially lead to spatial disorientation and confusion.

In the CDR 2 group, $46.7 \%$ of falls were of "ignored" cause, probably because the cognitive impairment prevents recall, and because most falls occurred in the absence of a witness caregiver. This might suggest that many falls occurred when the patient was alone, during walking or risky activities, and was unable to avoid them as a result of postural instability or lack of balance strategies. Dizziness and instability were frequent causes of fall in the CDR 1 group, which might explain the relatively higher frequency of recurrent falls in this group.

The actual frequency of occurrence of falls is difficult to estimate because of the following reasons: some falls are not remembered or go unseen by caregivers, some are not considered a fall according to the caregivers' judgment and caregivers may underreport a fall if it occurred as a result of their own negligence. In a study conducted by Eriksson et al., ${ }^{14} 24$ falls ( $9 \%$ ) were not reported by caregivers.

Our results suggest that more specific risk factors should be assessed, such as those addressed by Pelfolk et al. ${ }^{6}$ These researchers found that $36.1 \%$ of the variance in falls could be explained by being dependent in hygiene, displaying verbally disruptive/attention-seeking behavior, being able to rise from a chair, walking with assistive devices, and participating in outdoor walks, observed through logistic regression.

As falls are unpredictable events it is a laborious task to determine each underlying risk factor and interaction among them. Soriano et al. ${ }^{40}$ described a total of 25 risk factors for falls. This accounts for the fact that prevention strategies are hard to implement, and justifies why many preventive strategies are not as effective as desired.

These results reinforce the hypothesis that falls in $\mathrm{AD}$ are mutifactorial and that their risk factors are highly interconnected. Preventative strategies considering all aspects should be implemented, most crucially those eliminating environmental risks, maintaining constant presence of caregivers, and providing physical and functional stimulation, both in mild and moderate AD. Concluding, in our sample, previously well-established fall risks were not associated with an increase in the occurrence of falls in $\mathrm{AD}$, in either mild or moderate stages. As cited by Eriksson et al., ${ }^{14}$ "Conventional risk factors for falling explain a much smaller portion of the variations in falls among people 
with dementia than without dementia", a point on which we agree.

\section{References}

1. Tinetti ME, Speechley M, Ginter SF. Risk factors for falls among elderly persons living in the community. N Engl J Med 1988;319:1701-1707.

2. Moura RN, Santos FC, Dremier M, Santos LM, Ramos LR. Quedas em idosos: fatores de risco associados. Gerontologia 1999;7:15-21.

3. Ramos LR, Simões EJ, Albert MS. Dependence in activities of daily living and cognitive impairment strongly predicted mortality in older urban residents in Brazil: a 2-year followup. J Am Geriatr Soc 2001;49:1168-1175.

4. Perracini MR. Fatores associados a quedas em coorte de idosos residentes na comunidade. Rev Saúde Pública 2002;36:709-716.

5. Härlein J, Dassen T, Halfens RJ, Heinze C. Fall risk factors in older people with dementia or cognitive impairment: a systematic review. J Adv Nurs 2009;65:922-933.

6. Pelfolk T, Gustafsson T, Gustafsson Y, Larlsson S. Risk factors for falls among residents with dementia living in group dwelling. Int Psychogeriatr 2009;21:187-194.

7. Camicioli R, Licis L. Motor impairment predicts falls in specialized Alzheimer care unit. Alzheimer Dis Assoc Disord 2004;18:214-218

8. Verghese J, Buschke H, Viola L, et al. Validity of divided attention tasks in predicting falls in older individuals: a preliminary study. J Am Geriatr Soc 2002;50:1572-1576.

9. Thapa PB, Gideon P, Fought RL, Ray WA. Psychotropic drugs and risk of falls in ambulatory nursing home residents. Am J Epidemiol 1995;142:2002-2011.

10. Sterke CS, Verhangen AP, van Beeck EF, van der Cammen TJ. The influence of drug use on fall incidents among nursing home residents: a systematic review. Int Psychogeriatr 2008; 20:890-910.

11. Detweiller MB, Murphy PF, Kim KY, Myers LC, Ashai A. Schedule medications and falls in dementia patients utilizing a wander garden. Am J Alzheimers' Dis Other Dement 2009;24:322-332.

12. Brody EM, Kleban MH, Moss MS, Kleban F. Predictors of falls among institutionalized women with Alzheimer's disease. J Am Geriatr Soc 1984;32:877-882.

13. van Doorn C, Gruber-Baldini AL, Zimmerman S, et al. Dementia as a risk factor for falls and fall injuries among nursing home residents. J Am Geriatr Soc 2003;51:1213-1218.

14. Eriksson S, Gustafson Y, Lundin-Olsson L. Risk factors for falls in people with and without a diagnose of dementia living in residential care facilities: a prospective review. Archives of Gerontology and Geriatrics 2008;46:293-306.

15. Neyens JCL, Dijcks BPJ, van Haastregt JCM, et al. The development of a multidisciplinary fall risk evaluation tool for demented nursing home patients in the Netherlands. BMC Public Health 2006;6:74-81.

16. Oliver D, Connelly JB, Victor CR, et al. Strategies to prevent falls and fractures in hospitals and care homes and effect of cognitive impairment: systematic review and meta-analyses. BMJ 2006; doi 10.1136/bmj.39049.706493.55.

17. Mckhann G, Drachman D, Folstein M, Katzman R, Price D, Stadlan EM. Clinical diagnosis of Alzheimer's disease: report of the NINCDS-ADRDA work group under the auspices of the Department of Health an Human Services Task Force on Alzheimer's Disease. Neurology 1984;34:939-944.

18. Hughes CP, Berg L, Danziger WL, Coben LA, Martin RL. A new clinical scale for the staging of dementia. Bri J Psychiatry 1982;140:566-572; updated by Morris J. The CDR: current version and scoring rules. Neurology. 1993;43:2412-2413.

19. Smith GE, Ivnik RJ. Normative Neuropsychology. In: Petersen RC. Mild Cognitive Impairment. New York: Oxford 2003:63-88.

20. Gélinas I, Gauthier L, Mcintyre M, Gauthier S. Development of a functional measure for persons with Alzheimer's Disease: the disability assessment for dementia. Am J Occup Ther 1999;53:471-481.

21. Alexopoulos GS, Abrans RC, Young RC, Shamoian CA. Cornell Scale for Depression in Dementia. Biol Psychiatry 1988; 23:271-284.

22. Bueno-Cavanillas A, Padilla-Ruiz F, Jiménez-Moleón JJ, Peinado-Alonso CA, Gálvez-Vargas R. Risk factors in falls among the elderly according to extrinsic and intrinsic precipitating causes. Eur J Epidemiol 2000;16:849-859.

23. Stalenhoef PA, Diederiks JPM, Knottnerus JA, Kester ADM, Crebolder HFJM. A risk model for the prediction of recurrent falls in community-dwelling elderly: a prospective cohort study. J Clin Epidemiol 2002;55:1088-1094.

24. Rubenstein LZ, Josephson KR, Robbins AS. Falls in the nursing home. Ann Intern Med 1994;121:442-451.

25. Buchner DM, Larson EB. Falls and fractures in patients with Alzheimer-type dementia. J Am Med Assoc 1987;257:1492-1495.

26. Asada T, Kariya T, Kinoshita T, et al. Predictors of Fall-related injuries among community-dwelling elderly people with dementia. Age Aging 1996;25:22-28.

27. Ballard CG, Shaw F, Lowery K, McKeith I, Kenny R. The prevalence, assessment and associations of falls in dementia with Lewy bodies and Alzheimer's disease. Dement Geriatr Cogn Disord 1999;10:97-103.

28. Kenny RA, Richardson DA, Steen IN, Mckeith IG, Bond J, Shaw FE. Predictors of further falls in patients with cognitive impairment and dementia attending the casualty department. Age Ageing 2000;29:A23.

29. Bassiony MM, Rosenblatt A, Baker A, et al. Falls and age in patients with Alzheimer's Disease. J Nerv Ment Dis 2004; 192:570-572.

30. Horikawa E, Matsui T, Arai H, Seki T, Iwasaki K, Sasaki H. 
Risk of falls in Alzheimer's disease: a prospective study. Intern Med 2005;44:717-721.

31. Rahkonen T, Eloniemi-Sulkava U, Riassanen S; et al. Dementia with Lewy bodies according to the consensus criteria in a general population aged 75 years or older. J Neurol Neurosurg Psychiatry 2003;74:720-724.

32. Román GC, Tatemichi TK, Erkinjuntti T, et al. Vascular dementia: diagnostic criteria for research studies. Report of the NINDS-AIREN international workshop. Neurology 1993; 43:250-260.

33. Camarano, AM. Envelhecimento da população brasileira: uma contribuição demográfica. In: Freitas EV, Py L, Cançado FAX, Doll J, Gorzoni ML. Tratado de Geriatria e Gerontologia. Rio de Janeiro: Editora Guanabara Koogan; 2006;10:88-105.

34. Diogo, MJD. Modalidades de assistência ao idoso e à família: impacto sobre a qualidade de vida. In: Freitas EV, Py L, Cançado FAX, Doll J, Gorzoni ML. Tratado de Geriatria e Gerontologia. Rio de Janeiro: Guanabara Koogan; 2006:1383-1387.

35. Born T, Boechat NS. A qualidade dos cuidados ao idoso institucionalizado. In: Freitas EV, Py L, Cançado FAX, Doll J, Gorzoni ML, (editors). Tratado de Geriatria e Gerontologia. Rio de Janeiro: Guanabara Koogan; 2006:1131-1141.

36. Lemos ND, Medeiros, SL. Suporte social ao idoso dependente.
In: Freitas EV, Py L, Cançado FAX, Doll J, Gorzoni ML, (editors). Tratado de Geriatria e Gerontologia. Rio de Janeiro: Guanabara Koogan; 2006:1227-1233.

37. Krueger PD, Brazil K, Lohfeld LH. Risk factors for falls and injuries in a long-term care facility in Ontario. Can J Public Health 2001;92:117-120.

38. Allan LM, Ballard CG, Rowan EN, Kenny RA. Incidence and prediction of falls in dementia: a prospective study in older people. PLoS ONE 2009;4:e5521-8.

39. Kolanowski A, Fick, Waller JL, Ahern F. Outcomes of antipsychotic drug use in community-dwelling elders with dementia. Arch Psychiatr Nurs 2006;20:217.

40. Soriano TA, DeCherrie LV, Thomas DC. Falls in the community-dwelling older adult: a review for primary-care providers. Clin Interv Aging 2007;2:545-553.

41. Yamaguchi K. Falls in patients with dementia. Clin Calcium 2008; 18:1588.

42. Holmes C, Lovestone S. Long-term cognitive and functional decline in late onset Alzheimer's disease: therapeutic implications. Age Aging 2003;32:200-204.

43. Fitzgerald TG, Hadjistavropoulos t, MacNab YC. Caregiver fear of falling and functional ability among seniors residing in long-term care facilities. Gerontology 2009;55:460-467. 